\title{
Daily Interpersonal Stress and the Stressor-Vulnerability Model of Alcohol Use
}

\author{
Stephen Armeli \\ Farleigh Dickinson University \\ Tracy DeHart \\ Loyola University Chicago, tdehart@luc.edu \\ Howard Tennen \\ University of Connecticut School of Medicine and Dentistry \\ Michael Todd \\ Glenn Affleck \\ University of Connecticut School of Medicine and Dentistry
}

Follow this and additional works at: https://ecommons.luc.edu/psychology_facpubs

Part of the Psychology Commons

\section{Recommended Citation}

Armeli, S, T DeHart, H Tennen, M Todd, and G Affleck. "Daily Interpersonal Stress and the

Stressor-Vulnerability Model of Alcohol Use." Journal of Social and Clinical Psychology 26(8), 2007.

This Article is brought to you for free and open access by the Faculty Publications and Other Works by Department at Loyola eCommons. It has been accepted for inclusion in Psychology: Faculty Publications and Other Works by an authorized administrator of Loyola eCommons. For more information, please contact ecommons@luc.edu.

\section{(c) $($ ) $\Theta$}

This work is licensed under a Creative Commons Attribution-Noncommercial-No Derivative Works 3.0 License. (c) Guilford Press, 2007. Reprinted with permission of The Guilford Press. 


\title{
DAILY INTERPERSONAL STRESS AND THE STRESSOR-VULNERABILITY MODEL OF ALCOHOL USE
}

\author{
STEPHEN ARMELI \\ Fairleigh Dickinson University \\ TRACY DEHART \\ Loyola University Chicago \\ HOWARD TENNEN \\ University of Connecticut Health Center \\ MICHAEL TODD \\ Prevention Research Center \\ GLENN AFFLECK \\ University of Connecticut Health Center
}

\begin{abstract}
We used an experience sampling design to examine the within-person, within-day associations among interpersonal stress, negative affect, and alcohol use, and how these associations varied as a function of alcohol-outcome expectancies (AOEs), avoidance coping style, sex, and neuroticism. Ninety-eight community adult drinkers who wanted to reduce their alcohol consumption (49 women) reported for 21 days on their interpersonal stress and affect (three times per day), and alcohol use (as it occurred) using hand-held computers. Several individual difference factors interacted with daytime interpersonal stress and afternoon negative affect in predicting nighttime alcohol use, with individuals high in careless unconcern AOEs or low in impairment AOEs demonstrating stronger positive associations be-
\end{abstract}

Stephen Armeli, Department of Psychology, Fairleigh Dickinson University; Tracy DeHart, Department of Psychology, Loyola University Chicago; Howard Tennen, Department of Community Medicine and Health Care, University of Connecticut Health Center; Michael Todd, Prevention Research Center, Berkeley, CA; Glenn Affleck, Department of Community Medicine and Health Care, University of Connecticut Health Center.

This research was supported by grants R21-AA15691-01, T32-AA07290, and P50-AA03510 from the National Institute on Alcohol Abuse and Alcoholism. Correspondence regarding this article should be addressed to Stephen Armeli, Department of Psychology, Fairleigh Dickinson University, 1000 River Road, Teaneck, NJ 07666. E-mail: armeli@fdu.edu. 
tween daytime stress and negative affect and nighttime drinking. Daytime drinking and individual difference factors also interacted in predicting nighttime interpersonal stress, with individuals high in careless unconcern AOEs or those low in impairment AOEs or avoidance coping style demonstrating the strongest positive associations between daytime drinking and nighttime stress. The interactive effects in predicting drinking outcomes were generally limited to days on which some interpersonal stress occurred.

The social learning-based Stressor-Vulnerability Model (SVM) of alcohol use maintains that what individuals learn about the effects of consuming alcohol (i.e., alcohol-outcome expectancies [AOEs]) and their ability to manage stressful life situations are key risk factors in the development of maladaptive drinking patterns such as using alcohol to cope (Bandura, 1969; Maisto, Carey, \& Bradizza, 1999; Marlatt \& Gordon, 1985). More specifically, the basic SVM asserts that individuals who expect alcohol to result in a variety of positive outcomes or who in general want to avoid dealing with problems should be more likely to use alcohol when experiencing stress and associated negative moods (Cooper, Russell, \& George, 1988). Few studies, however, have examined the day-to-day unfolding of stressors, negative affect, and drinking, and how these associations are related to these risk factors. This is unfortunate given that treatment interventions designed for stress- and negative affect-related drinking, such as coping skills training, are increasingly targeted at within-person processes-that is, training individuals to respond more effectively to "high risk" situations, such as everyday stressors and negative affective states, when encountered (Witkiewitz \& Marlatt, 2004). For these interventions to succeed, research must directly model within-person relations to better understand the precipitating circumstances and whether individual differences in the SVM dimensions are related to these processes.

In one of the few studies to examine the relationship between the SVM risk factors and proximal (same-day) stress-drinking relations, Armeli, Carney, Tennen, Affleck, and O'Neil (2000) provided important insights into these processes. Consistent with findings from investigations using more traditional research designs (e.g., Cooper, Russell, Skinner, Frone, \& Mudar, 1992), Armeli et al. found that men with stronger positive AOEs, relative to others, drank more on high-stress versus low-stress days. In contrast, individuals high on avoidance coping showed no evidence of greater drinking on high-stress days; in fact among certain individuals, higher levels of avoidance coping were associated with decreased drinking on high-stress days (see also Armeli, Todd, \& Mohr, 2005). Such contradictory findings underscore the importance of not in- 
ferring within-person processes from research designs that do not assess this level of analysis (Tennen, Affleck, Armeli, \& Carney, 2000).

Armeli et al. (2000) also extended the SVM by examining individual differences in so-called negative AOEs, such as careless unconcern (e.g., becoming irresponsible, having little concern for doing things well and what others think of you) and cognitive and physical impairment (e.g., becoming clumsy, less coordinated). Interestingly, inclusion of careless unconcern AOEs into the predictive models rendered the moderating effects of positive AOEs nonsignificant. More specifically, it was men who strongly endorsed the belief that drinking would result in a sense of carelessness, not general positive outcomes, who demonstrated the strongest evidence of stress-related drinking. The effect of careless unconcern was interpreted as being due to the reinforcing nature of alcohol's detrimental effects on cognitive processes related to self-awareness (Hull, 1987) and attention (Josephs \& Steele, 1990; Steele \& Josephs, 1990). That is, for high careless unconcern individuals, alcohol's anticipated effects of decreasing self-awareness and reducing attentional capacity (i.e., becoming less aware of and concerned with the day's problems) might be especially desirable, and thus lead to relatively greater drinking on high-stress days.

Some evidence was also found for a buffering effect of impairment AOEs on the daily stress-alcohol use association. Specifically, men with strong expectations of impairment drank relatively less on high- versus low-stress days. It was posited that anticipation of becoming physically impaired-and its effect one's ability to deal with problems-might have deterred such individuals from drinking on high-stress days.

The central purpose of the present study was to examine further how the SVM risk factors (including careless unconcern and impairment AOEs) were associated with the day to day unfolding of stressful experiences and alcohol use. Although Armeli et al.'s (2000) study represented an important first step in modeling how individuals differ with respect to these processes, several key issues remain to be addressed. First, at the daily level of analysis, Armeli et al.'s study was essentially cross-sectional, with assessments of stress and alcohol use occurring together at the end of the day. Thus, an equally plausible interpretation of their findings is that among vulnerable individuals, stress does not cause drinking, but drinking results in increased stress or perceptions of stress (see Figure 1). The possibility of bidirectional effects between stress and alcohol use is especially relevant for certain types of stressors, such as interpersonal problems. Interpersonal problems have been identified as important drinking triggers (Annis \& Graham, 1995; Marlatt \& Gordon, 1985) and-due to alcohol's general disinhibiting effects, impairment of decision-making abilities, and associated expectations of increased ag- 


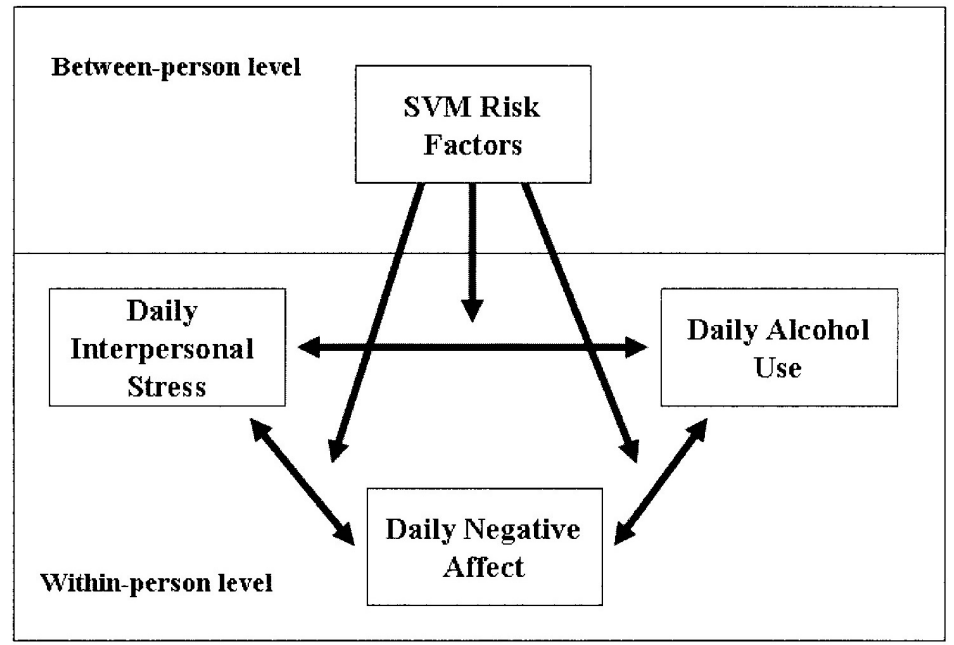

FIGURE 1. Theoretical model of the daily interpersonal stress-related drinking and the SVM risk factors.

gressiveness (Dawson, 1996; Kantor \& Straus, 1989; Kaufman-Kantor \& Asdigian, 1997) — as an outcome of drinking. Thus, in the present study we examined whether the SVM risk factors moderated the association between daytime interpersonal problems and evening alcohol use and the association between daytime alcohol use and evening interpersonal problems.

Another goal of the present study was to better elucidate the mechanisms underlying daily stress-related drinking. Specifically, Armeli et al.'s (2000) single-item measure of stress confounded stressor appraisal and affective response to the event. In the present study we separately measured stress appraisals (i.e., importance of interpersonal problems) and negative affect (see Figure 1). This allowed us examine a key premise of tension-reduction theory (Conger, 1956; Frone, Barnes \& Farrell, 1994; Greeley \& Oei, 1999): that drinking is used to reduce negative affective states caused by stressful events. More specifically, examining both interpersonal stressors and negative affect allowed us to test whether each is a unique predictor of alcohol use or whether-as specified in most models of tension reduction/stress-related drinking - negative affect mediates the effects of stress on alcohol use. Understanding whether the SVM risk factors are associated with increased drinking reactivity to general negative affect states or to specific types of stressors, such as interpersonal problems, will help to better 
tailor interventions focusing on coping skills training. Thus, the central aims of the study are as follows:

Hypothesis. The within-person associations between daytime interpersonal problems and nighttime alcohol use and between daytime negative affect and nighttime alcohol use will be stronger in the positive direction for individuals possessing high levels of avoidance coping styles, general positive and careless unconcern AOEs, and low levels of impairment AOEs.

Exploratory Goal. Examine how the within-person association between afternoon alcohol use and nighttime interpersonal problem importance varies as a function of the SVM risk factors.

In all models we controlled for individual differences in neuroticism. We included neuroticism because of consistent evidence regarding its association with (1) negative affect reactivity to daily interpersonal stress (Bolger \& Zuckerman, 1995; Gunthert, Cohen, \& Armeli, 1999; Zautra, Affleck \& Tennen, 2005), (2) avoidance coping style (e.g., Bouchard, 2003), and (3) retrospective reports of drinking to cope with stress and negative affect (Cooper, Frone, Russell, \& Mudar, 1995). Thus, controlling for neuroticism would allow us to rule out third variable confounding for any significant moderating effects of the SVM risk factors. We also controlled for daily positive affective states because prior research has shown it to be a robust predictor of proximal (same-day) drinking (e.g., Collins et al., 1998; Swendsen et al., 2000). Failure to account for variation in drinking related to positive affect might attenuate the within-person stress- and negative affect-drinking relations.

Finally, we examined these predictions in a sample of individuals who were drinking hazardously and who wished to drink more sensibly, but who do not meet criteria for alcohol abuse or dependence (variously referred to as "heavy drinkers" or "problem drinkers" [Institute of Medicine, 1990]). Given the high prevalence of these individuals (NIAAA, 2007), understanding the processes and risk factors (specifically those amenable to change such as the SVM factors) that might underlie heavy drinking and its relation to interpersonal conflict has important public health implications.

\section{METHOD}

\section{PARTICIPANTS}

Through newspaper advertisements, we recruited community adult drinkers who were concerned about their alcohol use and were interested in reducing their drinking. Participants were included who were drinking at potentially hazardous levels, defined as above 12 drinks 
weekly for women and 15 drinks weekly for men. Individuals who were alcohol dependent, whose continued drinking represented an immediate health hazard, who required a referral for formal treatment, or who were under 21 or over 60 years of age were excluded or referred to other studies. The present analyses concern the pre-brief intervention (baseline) phase of the overall study. The final sample ${ }^{1}$ of 98 ( $n=49$ women) was predominantly Caucasian $(n=93,95 \%)$ with a mean age of 43.5 years $(S D=8.69)$ and an average of 16.0 years of education $(S D=2.85)$. Most of the participants were employed ( $90 \%$ ), and they had a median annual income level of $\$ 60,001-\$ 70,000$. Participants were paid for their participation.

\section{PROCEDURE AND MEASURES}

Upon entering the study, participants completed a questionnaire that included the measures of alcohol-outcome expectancies, avoidance coping style, and neuroticism. They were then trained to recognize various drink sizes (e.g., beer sizes were $8 \mathrm{oz}, 10 \mathrm{oz}, 12 \mathrm{oz}$, etc.) and beverage subtypes (e.g., regular, light, ale/imported, and low alcohol) and to complete an electronic interview by using a hand-held computer (PSION Organizer Model LZ; PSION, Concord, MA) that has been shown to be user-friendly in previous studies (see Collins et al., 1998; Mohr et al., 2001). Then, for 21 days, participants reported on their interpersonal problems and affect in an interval/signal-contingent fashion and their alcohol consumption in an event-contingent fashion. Specifically, at random times during each of three intervals (between 10:00 and 11:30 a.m.; between 3:00 and 4:30 p.m.; and between 8:00 and 9:30 p.m.), participants were prompted with an audible beep to report on their interpersonal problems and their affect during the previous interval (or from waking to the first interview). We also provided participants with missed-interview booklets in the event that they could not complete the electronic interview. Compliance with the daily interviews was high. Across 6,174 possible interviews, 5533 (89.6\%) electronic interviews were completed when prompted. An additional 427 interviews $(6.9 \%$ of the possible interviews) were recorded in missed-interview booklets, resulting in an overall $96.5 \%$ compliance rate for the daily interviews.

1. This is the same sample used by Todd et al. (2005), who examined the negative interpersonal stress-drinking and negative affect-drinking associations at the interval level of analysis (i.e., morning, afternoon, and evening), not how daytime interpersonal stressors predicted nighttime drinking or how daytime drinking affected nighttime interpersonal stressors. Additionally, Todd et al. did not examine alcohol-outcome expectancies and avoidance coping as predictors of these within-person associations. 
Alcohol consumption was recorded as it occurred using one of two methods (see Mohr et al., 2001, for more detail). If participants anticipated drinking for an extended period of time, they initiated a "start drink" command and the computer would prompt them once an hour to record what they had consumed since the last prompt. Otherwise, they could record each drink as it was consumed. Participants were also given missed-drink interview booklets, which were to be used when it was impossible to record a drink on the computer (only $5.0 \%$ of the drinks were reported in booklets). During this portion of the study, participants were instructed to continue their customary pattern of drinking.

\section{Individual Difference Measures}

Alcohol-Outcome Expectancies (AOEs). We used the 40-item, true/ false version of the Alcohol Effects Questionnaire (AEQ; Rohsenow, 1983). Participants responded to the items by indicating what they personally experienced after having a few drinks. The AEQ has six positive expectancy subscales (global positive effects, social and physical pleasure, sexual enhancement, aggression and power, social expressiveness, and relaxation and tension reduction) and two negative subscales (cognitive/physical impairment and careless unconcern); we created subscale scores by summing together the appropriate items. Because previous research has found the six positive subscales to be highly correlated and representative of a single higher-order common factor (see Cooper et al., 1988; Cooper et al., 1992; George et al. 1995), and that this composite positive-expectancy measure moderates the daily stress-drinking association (Armeli et al., 2000), we formed an overall positive expectancy composite by averaging together the six positive subscales $(\alpha=.84)$. The careless unconcern and impairment subscales were examined separately ( $\alpha \mathrm{s}=.65$ and .68, respectively).

Avoidance Coping. We used the Denial (4 items), Mental Disengagement (4 items), and Behavioral Disengagement (4 items) subscales from the COPE (Carver, Scheier, \& Weintraub, 1989) to assess avoidance coping. Participants were instructed to indicate what they generally do and feel when they experience stressful events, and to rate the extent to which they used each strategy on a 4-point scale ( 1 = "I usually don't do this" to 4 = "I usually do this a lot"). For the proposed analyses an overall avoidance coping scale was created by summing together all of the items $(\alpha=.70)$.

Neuroticism. We used the 12-item neuroticism subscale from the (NEO-Five Factor Inventory; Costa \& McCrae, 1992). Items were rated on a 5 -point Likert scale ranging from 0 (strongly disagree) to 4 
(strongly agree). Responses were summed to create a composite ( $\alpha=$ .85).

\section{Electronic Interview Administered Measures}

Affect. During the second daily interview, individuals were prompted with the question: "How have you been feeling since the last interview?" and responded on a 5 -point scale $(0=$ "not at all" to $4=$ "extremely") to items taken from Watson, Clark and Tellegen's (1988) Positive and Negative Affect Schedule (PANAS) and Larsen and Diener's (1992) mood circumplex to assess their negative (sad, nervous, angry, lonely, disappointed) and positive (peppy, happy, and active) affect. We averaged together the appropriate items (for each day separately) to create composite positive and negative affect scores ( $\alpha$ s 71 and .79, respectively).

Alcohol Use. Real-time reports of the number of alcohol drinks consumed, drink sizes, and proof were converted to ounces of ethanol (each ounce of ethanol equals approximately two standard drinks). We created two drinking summary variables (i.e., sum of ounces of ethanol consumed): a daytime sum (i.e., waking to late afternoon [up to the second interview]) and a nighttime sum (i.e., after the afternoon interview). These time windows are consistent with previous research defining late afternoon as a natural transition period from the workday (especially for weekdays) to the leisure period (Dawson, 1996).

Interpersonal Stress. We created five items to assess common interpersonal problems (e.g., Ruehlman \& Karoly, 1991), especially those thought to precipitate alcohol consumption (Marlatt \& Gordon, 1985). Participants were prompted to rate the importance of "problems with others" concerning "demand/criticism," "disagreement," "rejected/ignored," "goal blocked," and "other conflicts" that might have occurred since the previous electronic interview. Response options ranged from 0 ("not at all") to 4 ("extremely") along with a "didn't happen" option (scored as a missing value). We created two separate daily interpersonal problem importance scores by summing the responses for the five items for the daytime (those reported during the first and second interviews, i.e., for the period from waking up until late afternoon) and for early evening (those reported during the third interview, i.e., for the period between late afternoon and early evening; interpersonal problems after this point were not recorded).

\section{ANALYTIC STRATEGY}

We tested the hypotheses using multilevel regression models estimated with HLM software (v6.03; Raudenbush, Bryk, Cheong, \& Congdon, 2004). For all models the Level 1 (daily) predictor variables were per- 
ARMELI ET AL.

TABLE 1. Descriptive Statistics

\begin{tabular}{|c|c|c|c|}
\hline & & $M$ & $S D$ \\
\hline 1. & Sex & - & - \\
\hline 2. & Positive AOE & 2.875 & 0.935 \\
\hline 3. & Careless Unconcern AOE & 2.347 & 1.335 \\
\hline 4. & Impairment AOE & 2.915 & 1.602 \\
\hline 5. & Avoidance Coping & 6.108 & 1.251 \\
\hline 6. & Neuroticism & 19.168 & 7.581 \\
\hline 7. & Positive Affect ${ }^{\mathrm{a}}$ & 1.836 & 0.621 \\
\hline 8. & Negative Affect ${ }^{\mathrm{a}}$ & 0.472 & 0.454 \\
\hline 9. & Daytime IPs ${ }^{\mathrm{a}}$ & 4.648 & 2.771 \\
\hline 10. & Nighttime IPs ${ }^{\mathrm{a}}$ & 1.521 & 1.614 \\
\hline 11. & Daytime Drinking $^{\mathrm{a}}$ & 0.231 & 0.383 \\
\hline 12. & Nighttime Drinking ${ }^{\mathrm{a}}$ & 1.494 & 0.775 \\
\hline
\end{tabular}

Note. $\mathrm{N}=95 ; \mathrm{AOE}=$ Alcohol outcome expectancies; $\mathrm{IPs}=$ Interpersonal problems. ${ }^{\mathrm{a}}$ Mean daily values.

son-mean-centered, thus allowing for the interpretation of Level 1 effects as within-person associations (Bryk \& Raudenbush, 1992; Schwartz \& Stone, 1998). All Level 2 (person) variables were grand-mean centered. Additionally, variance components were estimated for all Level 1 parameters. However, to achieve more parsimonious and stable models, nonsignificant slope variance components were fixed to zero and the models were re-estimated (Snijders \& Bosker, 1999). Finally, because number of drinks consumed is a count, we used the hierarchical generalized linear modeling (HGLM) setup (see Raudenbush \& Bryk, 2002) specifying a Poisson sampling model and log-link function with overdispersion; we report the unit-specific results.

In all models we included sex and neuroticism as main effects and as moderators of the within-person association of interest. Additionally, we included six day-of-the-week dummy codes (Saturday $=0$ ) to control for day-of-the-week trending. For models predicting nighttime outcomes from daytime variables, the corresponding daytime levels of the outcome are included as controls. All control variables were modeled as fixed effects.

We estimated the following models. First, as a preliminary step, we predicted afternoon negative affect from daytime interpersonal problem (IP) importance and its interactions with the SVM person factors; demonstrating that IP is related to negative affect would provide evidence for the possible mediating role of negative affect in the IP-drink- 
TABLE 2. Correlations Among the Person Factors

\begin{tabular}{|c|c|c|c|c|c|c|}
\hline & & 1 & 2 & 3 & 4 & 5 \\
\hline 1. & Sex & & & & & \\
\hline 2. & Positive AOE & $.206^{*}$ & & & & \\
\hline 3. & Careless Unconcern AOE & -.016 & $.401 *$ & & & \\
\hline 4. & Impairment AOE & -.012 & .111 & $.576^{*}$ & & \\
\hline 5. & Avoidance Coping & -.028 & $.214^{*}$ & $.206^{*}$ & $.311^{*}$ & \\
\hline & Neuroticism & .050 & $.312^{*}$ & $.193+$ & .102 & $.217^{*}$ \\
\hline
\end{tabular}

Note. $N=95 . \mathrm{AOE}=$ Alcohol outcome expectancies. $+p<.10,{ }^{*} p<.05$.

ing association. Next, we predicted nighttime drinking from daytime IP and its interactions with the SVM person factors. We then entered afternoon negative affect, along with its interactions with the SVM risk factors, into the model predicting nighttime drinking. This allowed us to examine how inclusion of negative affect altered the effect of daytime IP. We also included positive affect and its interactions with the SVM risk factors as controls in this model. A reduction in size of the coefficients associated with IP (and its interaction), along with significant coefficients for negative affect (and its interactions), would provide descriptive evidence for the mediating role of negative affect (Baron \& Kenny, 1986). We do not provide significance tests for indirect effects because such tests for nonlinear multilevel models have yet to be developed.

For our exploratory goal, we estimated a model predicting early evening IP from daytime alcohol use and its interactions with the SVM risk factors. This model was identical to the first step of the model predicting nighttime drinking, only here nighttime IP served as the dependent variable and daytime drinking as the key independent variable.

Because individuals only rated the importance of problems on days they occurred, we limited our main analyses to such days. This resulted in the number of usable days of data being reduced to $834(M=8.78$ days per person, $S D=5.19$ ). Three participants reported no interpersonal problems throughout the study and thus were excluded from the analyses, resulting in a usable sample size of 95 . We choose this strategy for several reasons. First, this strategy is consistent with Armeli et al. (2000) and thus allows for a more direct replication of their findings examining ratings of general stressfulness. Second, imputing values of IP for missing value days (i.e., treating days without interpersonal problems as "unimportant" problem days) assumes that such days are equivalent with respect to other types of stressors and constraints (or lack of constraints) related to drinking. Thus, examining drinking as a function of 
TABLE 3. Multilevel Regression Results Predicting Nighttime Drinking From Daytime Interpersonal Problems and SVM Risk Factors

\begin{tabular}{|c|c|c|c|}
\hline & $b$ & $S E$ & $p$ \\
\hline \multicolumn{4}{|l|}{ Between-Person Effects } \\
\hline Sex & -0.136 & .049 & .007 \\
\hline Impairment AOE & 0.025 & .037 & .503 \\
\hline Carelessness AOE & -0.067 & .048 & .168 \\
\hline Positive AOE & 0.158 & .080 & .051 \\
\hline Avoidance Coping & -0.041 & .039 & .288 \\
\hline Neuroticism & 0.001 & .006 & .804 \\
\hline \multicolumn{4}{|l|}{ Within-Person Effects } \\
\hline Sunday & -0.378 & .103 & $<.001$ \\
\hline Monday & -0.287 & .087 & .001 \\
\hline Tuesday & -0.272 & .098 & .006 \\
\hline Wednesday & -0.230 & .101 & .023 \\
\hline Thursday & -0.228 & .080 & .005 \\
\hline Friday & -0.056 & .083 & .500 \\
\hline Daytime Drinking & 0.017 & .045 & .711 \\
\hline Daytime IP & -0.006 & .007 & .374 \\
\hline \multicolumn{4}{|l|}{ Within $-\times$ Between-Person Effects } \\
\hline Daytime IP $\times$ Sex & 0.007 & .006 & .248 \\
\hline Daytime IP × Impairment AOE & -0.009 & .006 & .135 \\
\hline Daytime IP $\times$ Carelessness AOE & 0.019 & .007 & .006 \\
\hline Daytime IP $\times$ Positive AOE & -0.013 & .007 & .056 \\
\hline Daytime IP $\times$ Avoidance Coping & 0.008 & .007 & .246 \\
\hline Daytime IP $\times$ Neuroticism & 0.000 & .001 & .759 \\
\hline
\end{tabular}

Note. IP = Interpersonal problems. $\mathrm{b}=$ unstandardized regression coefficient (unit-specific estimates), SE $=$ robust standard errors. $D f$ for between-person effects $=88$; $d f$ for within-person and within $-\times$ between-person effects $=813$.

low and high interpersonal problem importance allows for a more controlled examination of the moderating effect of the SVM risk factors for this specific type of stressor. As a comparison, however, we also estimated supplemental models to examine how inclusion of noninterpersonal problem days alters the findings.

\section{RESULTS}

\section{DESCRIPTIVE STATISTICS}

Descriptive statistics for all of the study variables are shown in Table 1. Individuals drank more, on average, at night (about one and a half ounces of ethanol or approximately three standard drinks) compared to daytime (about a quarter of an ounce of ethanol or approximately half of a standard drink). In contrast, IP rating was higher, on average, during 
the daytime compared to early evening; however, the daytime measure encompasses a longer time period. Correlations among the person-level variables are shown in Table 2.

\section{MULTILEVEL REGRESSIONS}

Daytime interpersonal stress predicting afternoon negative affect Intercept and IP slope variance components were significant. ${ }^{2}$ None of the day-of-the-week contrasts was significant in predicting negative affect and thus they were removed from the model. Daytime drinking also was not related to afternoon negative affect, $\mathrm{b}=.024, p=.412$. Of central interest, daytime IP was related to afternoon negative affect, $\mathrm{b}=.052, p<$ .001 , but it did not interact with any of the person factors: $\mathrm{b}=.007, p=$ .208 (sex); $b=-.001, p=.932$ (impairment AOEs); $b=-.008, p=.127$ (careless unconcern AOEs); $\mathrm{b}=-.004, p=.463$ (positive AOEs); $\mathrm{b}=.002, p=$ .653 (avoidance); and $\mathrm{b}=.001, p=.298$ (neuroticism).

Daytime interpersonal stress predicting nighttime alcohol use Preliminary analyses indicated nonsignificant slope variance components for all of the following models; thus they were fixed to zero. The results from the final model are shown in Table 3. We found a significant interaction between daytime IP and careless unconcern AOEs, the form of which is shown in Figure 2 (top); we graphed the daytime IP-nighttime drinking association for high and low careless unconcern individuals (high and low values correspond to $\pm 1 S D$ from the mean of the careless unconcern scale; we used $\pm 1 S D$ as high and low values for moderators in all interaction graphs). Exponentiation of the simple slopes for low $\left(e^{-.30}=\right.$ $.97)$ and high $\left(e^{.018}=1.018\right)$ careless unconcern individuals offers a straightforward index of effect size. Specifically, we can state that a one-unit increase in daytime IP was associated with nighttime drinking changing by a factor of .97 (i.e., a decrease of $3.0 \%$ ) for low careless unconcern individuals and by a factor of 1.018 (i.e., an increase of $1.8 \%$ ) for high careless unconcern individuals. Calculation of the predicted drinking levels across low "stress" (an early day IP score equal to 1, the lowest value) and high "stress" (an early day IP score equal to 11, approximately the 90th percentile) days indicated a difference of approximately .25 ounces of ethanol (an increase of about half a standard drink) for high careless unconcern individuals and about .50 ounces of ethanol (a decrease of about one standard drink) for low careless unconcern individuals.

We also found a trend for an interaction between daytime IP and posi-

2. For the sake of brevity, we do not report the values for the variance components; these can be obtained by contacting the lead author. 

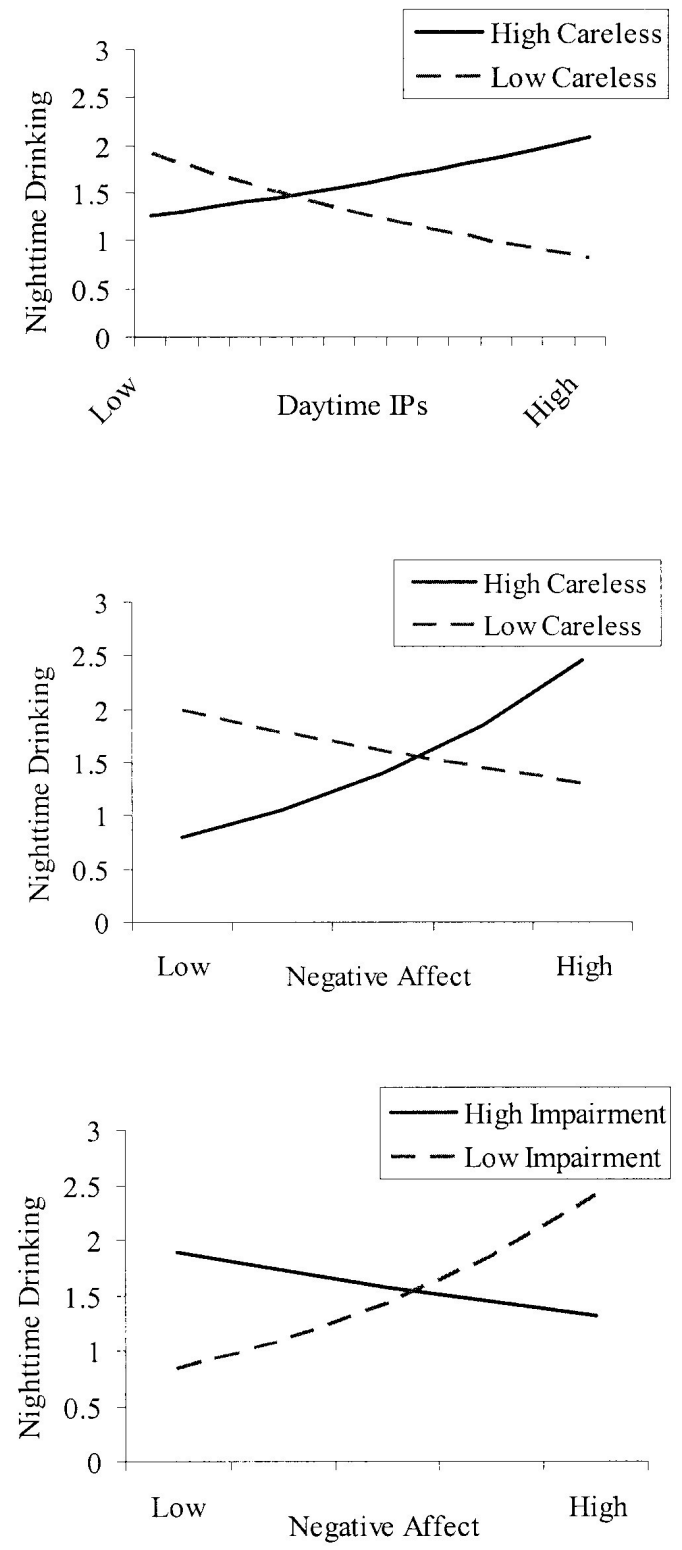

FIGURE 2. The relationship between afternoon interpersonal stress, negative affect and nighttime drinking as a function of SVM risk factors. 
TABLE 4. Multilevel Regression Results Predicting Nighttime Drinking From Daytime Interpersonal Problems, Afternoon Negative Affect and SVM Risk Factors

\begin{tabular}{lrrr}
\hline & $\boldsymbol{b}$ & $\boldsymbol{S E}$ & $\boldsymbol{p}$ \\
\hline Between-Person Effects & & & \\
Sex & -0.137 & .049 & .007 \\
Impairment AOE & 0.025 & .037 & .496 \\
Carelessness AOE & -0.068 & .048 & .165 \\
Positive AOE & 0.157 & .080 & .053 \\
Avoidance Coping & -0.042 & .039 & .285 \\
Neuroticism & 0.001 & .006 & .818 \\
Within-Person Effects & & & \\
Afternoon Negative Affect (NA) & 0.085 & .068 & .214 \\
Daytime IP (IP) & -0.007 & .008 & .345 \\
Within- $\times$ Between-Person Effects & & & \\
NA $\times$ Sex & 0.016 & .070 & .819 \\
NA $\times$ Impairment AOE & -0.106 & .046 & .021 \\
NA $\times$ Carelessness AOE & 0.147 & .062 & .018 \\
NA $\times$ Positive AOE & -0.013 & .077 & .863 \\
NA $\times$ Avoidance Coping & 0.068 & .046 & .135 \\
NA $\times$ Neuroticism & -0.002 & .007 & .732 \\
IP $\times$ Sex & 0.009 & .008 & .262 \\
IP $\times$ Impairment AOE & -0.003 & .007 & .588 \\
IP $\times$ Carelessness AOE & 0.013 & .007 & .071 \\
IP $\times$ Positive AOE & .007 & .143 \\
IP $\times$ Avoidance Coping & .0070 & .007 \\
IP $\times$ Neuroticism & 0.006 & .008 & .951 \\
\hline
\end{tabular}

Note. IP = Interpersonal problems. $b=$ unstandardized regression coefficient (unit-specific estimates), $S E$ $=$ robust standard errors. $D f$ for between-person effects $=88$; $d f$ for within-person and within $-\times$ between-person effects $=799$.

tive AOEs in the direction opposite to that predicted (i.e., those with higher positive AOEs showing more negative daily IP-drinking associations). To examine whether this interaction, or that involving careless unconcern was an artifact of multicollinearity, we removed each variable separately and re-estimated the model. Removal of the positive AOEs predictor did not affect the direction or significance of the careless unconcern AOE interaction; it did, however, result in the daytime IP $\times$ impairment AOEs interaction reaching significance, $\mathrm{b}=-.098, p=.039$. Removal of careless unconcern AOEs resulted in the coefficient for the daytime IP $\times$ positive AOEs interaction dropping to near zero, $\mathrm{b}=.024, p$ $=.646$. Given that the careless unconcern interaction was little changed and that the standard errors were not affected by deleting terms, we suspect that the findings are more likely due to suppression of common variance. 
Afternoon negative affect predicting nighttime alcohol use We next entered negative affect into the models predicting nighttime drinking from daytime IP; as stated above, positive affect and its interactive effects with the person-level variables were also included as controls. Table 4 shows the results from these models. (For simplicity of presentation, the effects for positive affect and its interactive effects are not shown-none of the predictors was significant. Also, the day-of-the-week contrasts are not shown; the effects were similar to those shown in Table 3.) Afternoon negative affect interacted with several of the SVM risk factors. ${ }^{3}$ Specifically, individuals with stronger careless unconcern AOEs had stronger positive associations between negative affect and nighttime drinking. It should be noted that the daily IP $\times$ careless unconcern AOEs interaction was reduced to marginal significance in this model. Descriptively, this suggests the possibility of mediation.

The form of the afternoon negative affect $\times$ careless unconcern AOEs interaction is shown in Figure 2 (middle). Exponentiation of the slopes for low and high careless unconcern individuals yielded values of 0.899 and 1.320, respectively. Thus, for example, a one-unit increase in afternoon negative affect for high careless unconcern individuals was associated with nighttime drinking increasing by $32 \%$. Estimated predicted drinking values across low negative affect (equal to 1 ) and high negative affect (equal to 5) days for high careless unconcern individuals indicated a difference of approximately 1.5 ounces of ethanol (an increase of about three standard drinks).

Impairment AOEs also moderated the association between afternoon negative affect and nighttime drinking, with participants who reported stronger expectations of impairment showing less positive associations between afternoon negative affect and nighttime drinking (see Figure 2 [bottom]). Exponentiated slopes for low and high impairment individuals were 1.297 and 0.914 , respectively. ${ }^{4}$

Finally, we tested for higher-order interactions among the SVM risk factors and sex. The only significant higher-order interaction involved

3. We re-estimated the final model substituting the tension-reduction subscale (of the AEQ) for the positive expectancy composite. The results were the same and the tension-reduction scale was not a significant moderator.

4. To examine whether inclusion of positive mood and its interactions with the SVM risk factors affected the findings, they were removed from the final model. The moderating effects of careless unconcern and impairment remained significant. Also, given the complexity of the model, we examined variance inflation factors (VIFs) for signs of multicollinearity. VIFs for all of the predictors were below the recommended cutoffs (e.g., $\geq 5$ or 10; Chatterjee \& Price, 1991; Cohen, Cohen, West, \& Aiken, 2003), indicating problems (all VIFs in our model were less than 4). 
sex and careless unconcern expectancies in predicting the negative affect-drinking slopes $(b=109, p=.043)$. Specifically, the moderating effect of carelessness AOEs was stronger for women compared to men.

Daytime alcohol use predicting nighttime interpersonal stress

Table 5 shows the results for the models predicting early evening IPs from daytime drinking. The day-of-the-week contrasts were not significant and thus were removed from the model. Daytime drinking interacted with several of the SVM risk factors. Individuals high in careless unconcern AOEs showed more positive associations between daytime drinking and early evening IPs. In Figure 3 (top) we graphed the predicted values of early evening IPs for daytime drinking ranging from 0 to 2 ounces of ethanol (approximately 0-4 standard drinks); 2 ounces of ethanol represented approximately the 97th percentile in daytime drinking); these values were used for all interactions in Figure 3.

Impairment AOEs also moderated the daytime drinking-early evening IP association, with high impairment individuals demonstrating a negative association and low impairment individuals demonstrating a positive association (see Figure 3 [middle]). Finally, avoidance coping style moderated the daytime drinking-early evening IP association, with high avoidance individuals demonstrating a negative association and low avoidance individuals demonstrating a positive association (see Figure 3 [bottom]). ${ }^{5}$

\section{Supplemental analyses}

Nighttime drinking across all days. To examine whether the findings differed if we included days on which no IPs were reported, we imputed values of IP importance for non-IP days. Specifically, non-IP days were recoded to a value of zero (equivalent to a low importance interpersonal problem). Aside from this, the specification of the models was identical to those described above. Results indicated that the previously significant moderating effect of careless unconcern AOEs on the daytime IP-nighttime drinking association was no longer significant, $\mathrm{b}=.007, p=$ .240. Moreover, the previously significant moderating effects of careless unconcern AOEs, $\mathrm{b}=.095, p=.097$, and impairment AOEs, $\mathrm{b}=-.071, p=$ .073 , on the daytime negative affect-nighttime drinking associations were reduced to marginal significance. For the models predicting night-

5. To test whether the effect of early-day drinking on later-day IP might be stronger among those who strongly endorsed power and aggression expectancies, we re-estimated the model substituting the power and aggression AEQ expectancy subscale for the total positive expectancy composite. The power and aggression scale did not moderate the daytime drinking-early evening IP association, and none of the significant findings changed. 

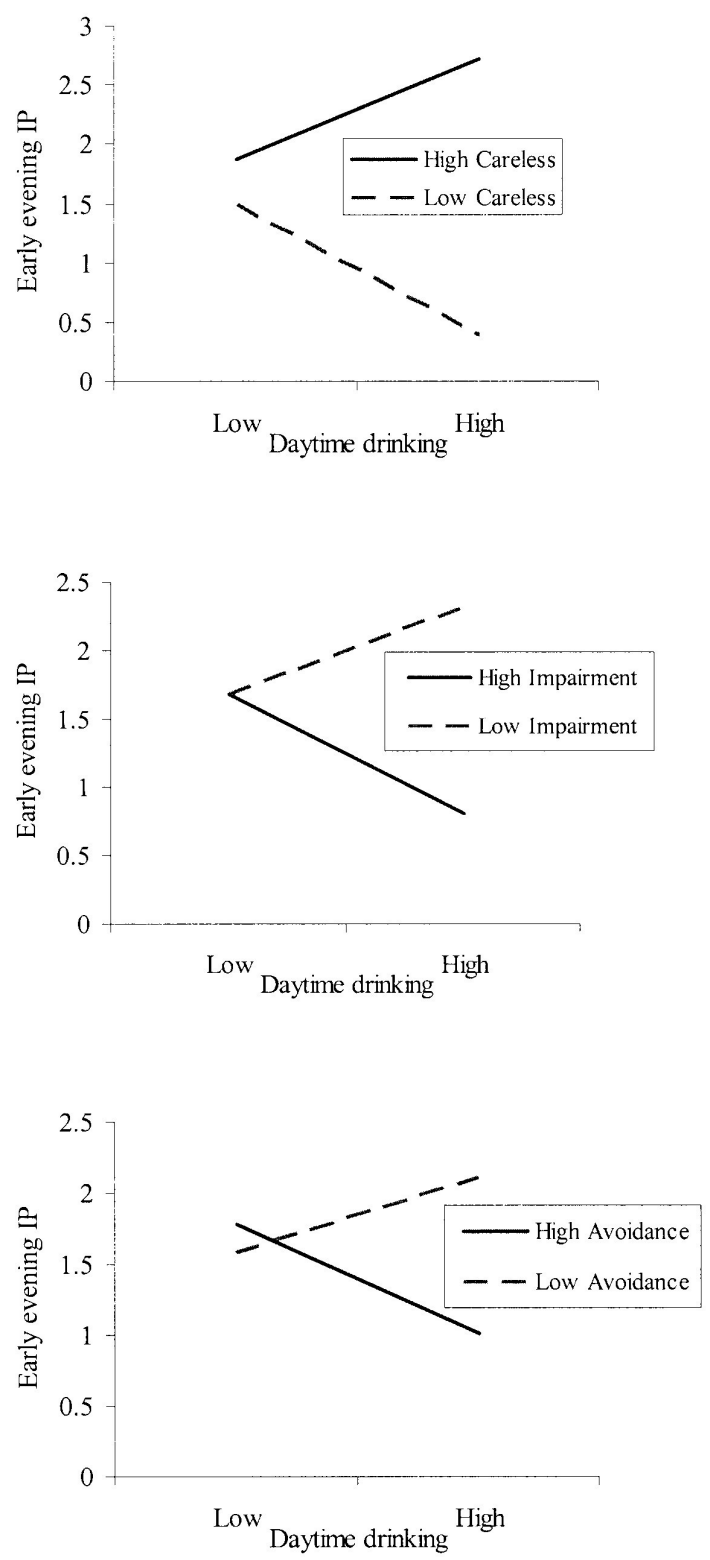

FIGURE 3. The relationship between daytime drinking and early evening interpersonal stress as a function of careless unconcern expectancies. 
TABLE 5. Multilevel Regression Results Predicting Nighttime Interpersonal Problems From Daytime Drinking and SVM Risk Factors

\begin{tabular}{lrrr}
\hline & $\boldsymbol{b}$ & $\boldsymbol{S E}$ & $\boldsymbol{p}$ \\
\hline Between-Person Effects & & & \\
Sex & 0.266 & .158 & .094 \\
Impairment AOE & -0.061 & .110 & .580 \\
Carelessness AOE & 0.223 & .159 & .164 \\
Positive AOE & 0.255 & .262 & .334 \\
Avoidance Coping & 0.020 & .137 & .884 \\
Neuroticism & 0.021 & .027 & .437 \\
Within-Person Effects & & & \\
Daytime IP & 0.154 & .038 & $<.001$ \\
Daytime Drinking (DD) & -0.061 & .149 & .681 \\
Within- $\times$ Between-Person Effects & & & \\
DD $\times$ Sex & 0.287 & .188 & .127 \\
DD $\times$ Impairment AOE & -0.275 & .119 & .021 \\
DD $\times$ Carelessness AOE & 0.359 & .154 & .020 \\
DD $\times$ Positive AOE & 0.110 & .190 & .563 \\
DD $\times$ Avoidance Coping & -0.240 & .114 & .035 \\
DD $\times$ Neuroticism & -0.030 & .019 & .121 \\
\hline
\end{tabular}

Note. $b=$ unstandardized regression coefficient (linear model), $S E=$ robust standard errors. $D f$ for between-person effects $=88$; $d f$ for within-person and within- $\times$ between-person effects $=819$.

time IPs from daytime drinking, the findings did not change with the exception of the moderating effect of impairment AOEs; this interaction was no longer significant, $\mathrm{b}=-.072, p=.13$.

Nighttime drinking on days with no IPs. We also examined the association between daytime affect and nighttime drinking on days when IPs were not reported. Results indicated that individuals drank more, on average, on days characterized by relatively higher positive affect, $b=.146$, $p=.019$. Afternoon negative affect, on average, was unrelated to nighttime drinking, $\mathrm{b}=-.093, p=.340$. The positive affect-drinking association did not vary as a function of the person-level variables. However, the negative affect-drinking association varied as a function of avoidance coping style, $\mathrm{b}=.212, p=.029$, and sex, $\mathrm{b}=.193, p=.050$, with individuals who characteristically use avoidance coping and women demonstrating positive associations and others demonstrating negative associations.

Daytime interpersonal stress and daytime drinking. We also examined the possibility that IP might demonstrate a qualitatively different association with daytime drinking. Thus, we predicted daytime drinking from 
IPs reported during the same period (i.e., from waking to the afternoon interview). This essentially was a cross-sectional analysis, and thus we did not examine the mediating role of afternoon affect. Results indicated a marginally significant interaction (in the direction expected by theory) between daytime IPs and positive AOEs, $\mathrm{b}=.049, p=.065$ with high positive AOEs individuals demonstrating a positive association and low positive expectancy individuals demonstrating a negative association.

\section{DISCUSSION}

The associations between daytime interpersonal stress and negative affect and nighttime alcohol use were related to individual differences in careless unconcern and impairment expectancies, but not to the more traditional social learning risk factors of positive outcome expectancies and avoidance coping style. Specifically, those with stronger careless unconcern expectancies and those with weaker impairment expectances demonstrated drinking patterns consistent with tension reduction theory. These effects were generally limited to days characterized by some interpersonal problems. We also found evidence that the association between early day drinking and later-day interpersonal stress was related to individual differences in careless unconcern and impairment expectancies and avoidance coping style. Specifically, individuals with stronger carelessness expectancies showed greater nighttime interpersonal stress on days with greater daytime drinking. In contrast, those with stronger impairment expectancies and avoidance coping styles showed less nighttime interpersonal stress on days with greater daytime drinking.

\section{INTERPERSONAL STRESS AS A PREDICTOR OF DRINKING}

Similar to Armeli et al.'s (2000) results, individuals with strong careless unconcern expectancies demonstrated evidence of stress-related drinking. These findings are consistent with the notion that, for such individuals, drinking on high-stress days might be driven by the anticipated effects of alcohol in terms of helping them shift their attention away from themselves and the day's problems. Such expected outcomes from drinking might be especially salient and desirable for high careless unconcern individuals in the context of certain types of interpersonal stressors (e.g., receiving criticism, being rejected or ignored). Past research suggests that in situations where individuals' self-evaluation is threatened, alcohol's ability to shift attention away from the self is thought to be especially rewarding (Hull, 1987). In contrast, among low careless unconcern individuals, interpersonal stress might have less of a 
priming effect on such drinking expectancies; thus, on such days these individuals tend to respond more adaptively by reducing their drinking levels.

Careless unconcern expectancies also moderated the relation between afternoon negative affect and nighttime drinking, and inclusion of this effect into the model reduced to marginal significance the interaction between careless unconcern expectancies and interpersonal stress. Descriptively, at least, this pattern indicates the possibility of a complex pattern of moderated mediation (see Kenny, Korchmaros, \& Bolger, 2003). Specifically, the occurrence of interpersonal problems might differentially affect (across low and high careless unconcern individuals) the salience and desirability regarding the sense of carelessness that will result from drinking. For high careless unconcern individuals-for whom such expectancies might become more salient and desirable-increased negative affect caused by interpersonal problems results in increased drinking. In contrast, for low careless unconcern individuals-for whom such expectancies are not as salient or are possibly viewed as undesirable-increased negative affect results in decreased drinking. Real-time assessment of individuals' drinking expectancies is needed to test this interpretation.

Drinkers with weaker impairment expectancies also demonstrated greater negative affect-related drinking. These findings are somewhat consistent with Armeli et al.'s (2000) results showing that strong expectations for impairment, among certain individuals, attenuated the stress-drinking association. Both studies indicate that although being positively associated with careless unconcern expectancies, impairment expectancies seem to have an opposite unique effect on the daily stress-alcohol link. Consistent with Armeli et al.'s interpretation, expectations of impairment (i.e., increased clumsiness and decreased cognitive efficiency) from drinking might be associated with the belief that such outcomes, during stressful times, would interfere with the use of more problem-focused coping strategies. Thus, our findings suggest that strong impairment expectancies might be viewed as a protective factor regarding tension-reduction drinking.

We also found some evidence that the nature of stress-related drinking might vary within day. Specifically, positive expectancies moderated (marginally) the association between daytime interpersonal problems and daytime drinking, with individuals with stronger positive expectancies demonstrating a stronger positive association. It should be noted that this was the only finding that supported the role of positive expectancies as a risk factor for stress-related drinking. That daytime interpersonal stress-related drinking was more prominent among individuals with stronger beliefs that drinking would result in outcomes 
such as increased social pleasure, expressiveness, and warmth suggests the possibility that drinking during different periods of the day might represent qualitatively distinct behaviors. For example, daytime interpersonal stress-related drinking (for high positive expectancy individuals) might have taken place in social situations (e.g., lunchtime with coworkers). Conversely, nighttime interpersonal stress-related drinking (for high carelessness individuals) might be less social and motivationally related to escaping problems and responsibility. Future studies assessing the social aspects of the drinking situation (e.g., Mohr et al., 2001) are needed to test these interpretations.

Finally, we found little evidence that avoidance coping style was associated with increased problem- or negative affect-related drinking (at least on days characterized by interpersonal problems). These findings, along with others (Armeli et al., 2000; Armeli et al., 2005), raise questions about the role of avoidance coping in stress-related drinking. One possibility is that individuals' reports of dispositional use of avoidance coping might draw upon experiences with more severe negative life events rather than everyday stressors. Reactions to everyday "micro-stressors" might share little in common with reactions to negative life events (Tennen \& Affleck, 2003).

An important caveat to the findings regarding nighttime drinking is that they were generally limited to days characterized by some level of conflict (i.e., at least one interpersonal problem was reported). Inclusion of days without any interpersonal conflict (and coded as an "unimportant problem" day) reduced the size and significance of the interactive effects. This pattern of findings is consistent with the idea that differential processes might govern stress-related drinking and experience-enhancement drinking (e.g., Cooper et al., 1995). A distinct set of expectancies might be primed on days on which interpersonal conflict occurs. Once activated, the desirability of anticipated drinking outcomes (e.g., not worrying about what others think) might be affected by problem and affect intensity, which in turn affects consumption (e.g., Armeli et al., 2005). In contrast, drinking on other days (e.g., days with festive gatherings) might be governed by distinct mechanisms. Some evidence for this explanation can be seen in our findings showing differential associations between drinking, affect, and the social learning factors on days with no interpersonal conflict. It should be noted that Armeli et al.'s (2000) findings concerning the moderating effects of careless unconcern expectancies were similarly based on data from days on which some sort of stressor was reported. Further research is needed to examine whether distinct mechanisms govern drinking on qualitatively different types of days. 


\section{DRINKING AS A PREDICTOR OF INTERPERSONAL STRESS}

We also found evidence that the association between interpersonal stress and alcohol use might be bidirectional, but the direction of this effect varied across persons. For example, individuals with stronger careless unconcern expectancies showed increased nighttime stress, and those with weaker expectancies showed decreased stress, on days with relatively greater daytime drinking. Taken together with the drinking findings, we could posit that not only do careless unconcern expectancies play a role in the decision-making process related to drinking, but they also might be, to some degree, self-confirming (see Kirsch, 1999). That is, strong endorsement of statements regarding the propensity to become irresponsible and careless about one's action might be associated with, upon drinking, actual decreases in regard for others and concern for good behavior, which in turn might result in the initiation or exacerbation of interpersonal conflict. In contrast, the negative association between daytime drinking and nighttime interpersonal stress demonstrated by individuals with weak careless unconcern expectancies might represent more of a classic stress-response dampening effect in which the effects of stressful events are lessened as a result of alcohol use (Sher, 1987). For such individuals, interpersonal behavior might be more affected by alcohol's calming and sedating effects.

Similar to the nighttime drinking findings, impairment expectancies had an effect opposite to that of careless unconcern, with high-impairment individuals showing a negative association between daytime drinking and nighttime problems. This also might represent evidence for the self-confirming nature of response expectancies, such that high-impairment individuals, upon drinking, might have become less aware cognitively and more lethargic physically. Such low-activity states might help to remove individuals from ongoing conflict or help to prevent the initiation of conflict.

Finally, among high-avoidance copers, daytime drinking was associated with lower levels of nighttime problems. One possibility is that avoidance coping style might be associated with the experiential aspects of drinking. High-avoidance copers might possess response expectancies (unmeasured in our study) that alcohol will help distract oneself from problems. Individuals high in such beliefs, due to their self-confirming nature, might be better able to disengage from such problems upon drinking. This would be distinct from our posited mechanism underlying the effects of careless unconcern expectancies, which had the opposite effect on the daytime drinking-nighttime interpersonal stress association. Careless unconcern expectancies might be more closely tied to escaping problems in a more reckless and maladaptive fashion (e.g., 
disregard for what others think, not caring about one's behavior) that, in some situations, exacerbate problems. In contrast, one's tendency to avoid problems as measured by the COPE (e.g., "I act as though it hasn't happened," "I say to myself 'this isn't real") might be more closely tied to beliefs that alcohol consumption will allow one to disengage in a more passive fashion. Future research is needed to establish the link between avoidance coping style and these posited response expectancies and to examine the possibility that, in some situations, avoidance coping style might act as a protective factor.

\section{CLINICAL IMPLICATIONS}

Our findings could have important implications for clinical interventions aimed at reducing stress- and negative affect-related drinking among problem drinkers. Specifically, the expectancies of careless unconcern and impairment have received far less attention because of their weak associations with average drinking levels (e.g., Leigh \& Stacy, 1993). Our results suggest that these expectancies are more important in terms of predicting maladaptive drinking patterns. Thus, interventions aimed at teaching skills to deal with high-risk situations, such as interpersonal stress and related distress, also might attempt to alter individuals' beliefs regarding these possible drinking outcomes. Decreasing expectations of carelessness, or increasing expectations of impairment, might not only reduce stress- and negative affect-related drinking, but also could help to decrease interpersonal conflict arising from drinking.

\section{LIMITATIONS AND CONCLUSIONS}

Although real-time data collection allowed us to examine the temporal ordering of variables as they unfold in everyday life, this methodology is not without its drawbacks. For example, event-contingent monitoring-such as the reporting of alcohol use as it occurs-is not verifiable. However, when the question of interest concerns the unfolding of phenomena within-day, electronic reporting, as opposed to other strategies (e.g., paper-and-pencil diaries), is the method of choice (Tennen, Affleck, Coyne, Larsen, \& DeLongis, 2006). We are also careful not to generalize beyond our sample, which consisted of a somewhat narrow band of Caucasian, middle to upper socioeconomic status, heavy social drinkers who wanted to reduce their alcohol use. Moreover, our person-level sample size was relatively small, thus limiting the power for detecting many of the higher-order interactions tested. Finally, we limited our focus to general interpersonal problems, thus ignoring subtypes of interpersonal stressors (e.g., problems with coworkers vs. family) as 
well as qualitatively different types of stressors (e.g., increased workload, financial problems) that might have had an influence on drinking. Future research examining a variety of stressor types might provide more robust findings.

Nevertheless, our findings showing individual differences expectancies and coping style related to different aspects of the within-person, within-day associations among interpersonal stress, negative affect, and drinking further demonstrate the importance of examining such associations at various theoretically meaningful levels of analysis.

\section{REFERENCES}

Annis, H. M., \& Graham, J. M. (1995). Profile types on the inventory of drinking situations: Implications for relapse prevention counseling, Psychology of Addictive Behaviors, 9, 176-182.

Armeli, S., Carney, M. A., Tennen, H., Affleck, G., \& O'Neil, T. (2000). Stress and alcohol use: A daily process examination of the stressor-vulnerability model. Journal of Personality and Social Psychology, 78, 979-994.

Armeli, S., Mohr, C., Todd, M., Maltby, N., Tennen, H., Carney, M. A. et al. (2005). Daily evaluation of anticipated outcomes from alcohol use among college students. Journal of Social and Clinical Psychology, 4, 767-792.

Armeli, S., Todd, M., \& Mohr, C. (2005). A daily process approach to individual differences in stress-related alcohol use. Journal of Personality, 73, 1657-1686.

Bandura, A. (1969). Principles of behavior modification. New York: Holt, Rinehart \& Winston.

Baron, R.M., \& Kenny, D. A. (1986). The moderator-mediator variable distinction in social psychological research: Conceptual, strategic, and statistical considerations. Journal of Personality and Social Psychology, 51, 1173-1182.

Bolger, N., DeLongis, A., Kessler, R. C., \& Schilling, E. A. (1989). Effects of daily stress on negative mood. Journal of Personality and Social Psychology, 57, 808-818.

Bolger, N., \& Zuckerman, A. (1995). A framework for studying personality in the stress process. Journal of Personality and Social Psychology, 69, 890-902.

Bouchard, G. (2003). Cognitive appraisals, neuroticism, and openness as correlates of coping strategies: An integrative model of adaptation to marital difficulties. Canadian Journal of Behavioural Science, 35, 1-12.

Bryk, A.S., \& Raudenbush, S.W. (1992). Hierarchical linear models: Applications and data analysis methods. Newbury Park, CA: Sage.

Carver, C. S., Scheier, M. F., \& Weintraub, J. K. (1989). Assessing coping strategies: A theoretically based approach. Journal of Personality \& Social Psychology, 56, 267-283.

Chatterjee, S., \& Price, B. (1991). Regression analysis by example (2nd ed.). New York: John Wiley and Sons.

Cohen, J., Cohen, P., West, S., \& Aiken, L. (2003). Applied multiple regression/correlation analysis for the behavioral sciences (3rd ed.). Hillsdale, NJ: Lawrence Erlbaum Associates.

Collins, R. L., Morsheimer, E. T., Shiffman, S., Paty, J. A., Gnys, M., \& Papandonatos, G. D. (1998). Ecological momentary assessment in a behavioral drinking moderation training program. Experimental and Clinical Psychopharmacology, 6, 306-315.

Conger, J. J. (1956). Alcoholism: Theory, problem and challenge: II. Reinforcement theory and the dynamics of alcoholism. Quarterly Journal of Studies on Alcohol, 17,296-305. 
Cooper, M. L., Frone, M. R., Russell, M., \& Mudar, P. (1995). Drinking to regulate positive and negative emotions: A motivational model of alcohol use. Journal of Personality and Social Psychology, 69, 990-1005.

Cooper, M. L., Russell, M., \& George, W. H. (1988). Coping, expectancies, and alcohol abuse: A test of social learning formulations. Journal of Abnormal Psychology, 97, 218-230.

Cooper, M. L., Russell, M., Skinner, J. B., Frone, M. R., \& Mudar, P. (1992). Stress and alcohol use: Moderating effects of gender, coping and alcohol expectancies. Journal of Abnormal Psychology, 101, 139-152.

Costa, P.T., \& McCrae, R.R. (1992). The NEO Personality Inventory Professional Manual. Odessa, FL: Psychological Assessment Resources.

Dawson, D. A. (1996). Temporal drinking patterns and variation in social consequences. Addiction, 91, 1623-1635.

Frone, M. R., Barnes, G. M., \& Farrell, M. P. (1994). Relationship of work-family conflict to substance use among employed mothers: The role of negative affect. Journal of Marriage and the Family, 56, 1019-1030.

George, W. H., Frone, M. R., Cooper, M. L., Russell, M., Skinner, J. B., \& Windle, M. (1995). A revised alcohol expectancy questionnaire: Factor structure confirmation and invariance in a general population sample. Journal of Studies on Alcohol, 56, 177-185.

Greeley, J., \& Oei, T. (1999). Alcohol and tension reduction. In K. E. Leonard \& H. T. Blane (Eds.), Psychological theories of drinking and alcoholism (2nd ed., pp. 14-53). New York: Guilford Press.

Gunthert, K., Cohen, L., \& Armeli, S. (1999). The role of neuroticism in the daily stress and coping process. Journal of Personality and Social Psychology, 77, 1087-1100.

Hull, J. G. (1987). Self-awareness model. In H. T. Blane \& K. E. Leonard (Eds.), Psychological theories of drinking and alcoholism (pp. 272-304). New York: Guilford Press.

Institute of Medicine. (1990). Broadening the base of treatment for alcohol problems. Washington, DC: National Academy Press.

Josephs, R. A., \& Steele, C. M. (1990). The two faces of alcohol myopia: Attentional mediation of psychological stress. Journal of Abnormal Psychology, 99, 115-126.

Kantor, G. K., \& Straus, M. (1989). Substance abuse as a precipitant of wife abuse victimizations. American Journal of Drug \& Alcohol Abuse, 15, 173-189.

Kaufman-Kantor, G., \& Asdigian, N. L. (1997). Gender differences in alcohol-related spousal aggression. In R. W. Wilsnack \& S. C. Wilsnack (Eds.), Gender and alcohol: Individual and social perspectives (pp. 312-334). Piscataway, NJ: Rutgers Center of Alcohol Studies.

Kenny, D. A., Korchmaros, J. D., \& Bolger, N. (2003). Lower level mediation in multilevel models. Psychological Methods, 8, 115-128.

Kirsch, I. (1999). How expectancies shape experience. Washington, DC: American Psychological Association.

Larsen, R.J., \& Diener, E. (1992). Promises and problems with the circumplex model of emotion. In M. S. Clark (Ed.), Review of personality and social psychology (pp. 25-59). Newbury Park, CA: Sage.

Leigh, B., \& Stacy, A. W. (1993). Alcohol outcome expectancies: Scale construction and predictive utility in higher order confirmatory models. Psychological Assessment, 5, 216-229.

Maisto, S. A., Carey, K. B., \& Bradizza, C. M. (1999). Social learning theory. In K. E. Leonard \& H. T. Blane (Eds.), Psychological theories of drinking and alcoholism (2nd ed., pp. 106-163). New York: Guilford Press.

Marlatt, G. A., \& Gordon, J. R. (1985). Relapse prevention: Maintenance strategies in the treatment of addictive behaviors. New York: Guilford Press. 
Mohr, C.D., Armeli, S., Tennen, H., Carney, M.A., Affleck, G., \& Hromi, A. (2001). Daily interpersonal experiences, context, and alcohol consumption: Crying in your beer and toasting good times. Journal of Personality and Social Psychology, 80, 489-500.

NIAAA (National Institute on Alcohol Abuse and Alcoholism). (2007). Helping patients who drink too much: A clinician's guide, revised. NIH Publication No. 07-3769. Washington, DC: NIH.

Raudenbush, S. W., \& Bryk, A. S. (2002). Hierarchical linear models: Applications and data analysis methods (2nd ed.). Newbury Park, CA: Sage.

Raudenbush, S., Bryk, A., Cheong, Y.F., \& Congdon, R. (2004). HLM 6: Hierarchical linear and nonlinear modeling. Lincolnwood, IL: Scientific Software International.

Rohsenow, D. J. (1983). Drinking habits and expectancies about alcohol's effects for self versus others. Journal of Consulting and Clinical Psychology, 51, 752-756.

Ruehlman, L.S., \& Karoly, P. (1991). With a little flak from my friends: Development and preliminary validation of the Test of Negative Social Exchange (TENSE). Psychological Assessment, 3, 97-104.

Schwartz,J. E., \& Stone, A. A. (1998). Strategies for analyzing ecological momentary assessment data. Health Psychology, 17, 6-16.

Sher, K. J. (1987). Stress response dampening. In H. T. Blane \& K. E. Leonard (Eds.), Psychological theories of drinking and alcoholism (pp. 227-271). New York: Guilford Press.

Snijders, T., \& Bosker, R. (1999). Multilevel analysis: An introduction to basic and advanced multilevel modeling. Thousand Oaks, CA: Sage Publications.

Steele, C. M., \& Josephs, R. A. (1990). Alcohol myopia: Its prized and dangerous effects. American Psychologist, 45, 921-933

Swendsen, J. D., Tennen, H., Carney, M. A., Affleck, G., Willard, A., \& Hromi, A. (2000). Mood and alcohol consumption: An experience sampling test of the self-medication hypothesis. Journal of Abnormal Psychology, 109, 198-204.

Tennen, H., \& Affleck, G. (2003).While accentuating the positive, don't eliminate the negative or Mr. In-between. Psychological Inquiry, 14, 163-169.

Tennen, H., Affleck, G., Armeli, S., \& Carney, M. A. (2000). A daily process approach to coping: Linking theory, research and practice. American Psychologist, 55, 626-636.

Tennen, H., Affleck, G., Coyne, J. C., Larsen, R. J., \& DeLongis, A. (2006). Paper and plastic in daily diary research: Comment on Green, Rafaeli, Bolger, Shrout, and Reis. Psychological Methods, 11, 112-118.

Todd, M., Armeli, S., Tennen, H., Carney, M. A., Ball, S. A., Kranzler, H. R. et al. (2005). Drinking to cope: A comparison of questionnaire and electronic diary reports Journal of Studies on Alcohol, 66, 121-129.

Watson, D., Clark, L. A., \& Tellegen, A. (1988). Development and validation of brief measures of positive and negative affect: The PANAS scales. Journal of Personality and Social Psychology, 54, 1063-1070.

Witkiewitz, K., \& Marlatt, A. G. (2004). Relapse prevention for alcohol and drug problems: That was Zen, this is Tao. American Psychologist, 59, 224-235.

Zautra, A. J., Affleck, G., \& Tennen, H. (2005). Dynamic approaches to emotions and stress in everyday life: Bolger and Zuckerman reloaded with positive as well as negative affects. Journal of Personality, 73, 1511-1538. 